\title{
Clinical analysis of chemo-resistance risk factors in endometriosis associated ovarian cancer
}

\author{
Tong Ren ${ }^{1+}$, Ting-Ting Sun ${ }^{1 \dagger}$, Shu Wang ${ }^{1 *}$, Jian Sun ${ }^{2}$, Yang Xiang ${ }^{1 *}$, Keng Shen ${ }^{1}$ and Jing-He Lang ${ }^{1 *}$
}

\begin{abstract}
Background: To analyze the clinical characteristics and chemo-resistance related factors of patients with resistant and non-resistant endometriosis-associated ovarian cancer (ovarian clear cell carcinoma and endometrioid carcinoma) by reviewing the data of epithelial ovarian cancer patients who received initial treatment in our hospital over a 12-year period.
\end{abstract}

Results: Among the 304 patients, 17.1\% were seen with platinum-based drug resistance. The ROC curve of continuous variables was drawn according to resistance situation, then they were grouped by age ( $<48$ or $\geq 48$ years), tumor size $(<7 \mathrm{~cm}$ or $\geq 7 \mathrm{~cm}$ ) and Ca125 ( $<90$ and $\geq 90 \mathrm{U} / \mathrm{ml})$. In univariate analysis, age $\geq 48$ years, initial symptom of abdominal distension or weight loss, abnormal preoperative serum Ca125, Ca1 $25<90 \mathrm{U} / \mathrm{ml}$, advanced FIGO stage, absence of endometriosis, bilateral tumors, lack of lymphadenectomy, positive lymph nodes, unsatisfactory initial cytoreduction surgery and history of breast cancer were all related to drug resistance in ovarian cancer. In multivariate analysis, advanced stage, lack of lymphadenectomy, positive lymph nodes and history of breast cancer were independent risk factors related to platinum-based drug resistance $(P<0.05)$.

Conclusion: For patients of endometriosis-related ovarian cancer, platinum-based drug resistance were associated with advanced FIGO stage, lack of lymphadenectomy, positive lymph nodes and history of breast cancer.

Keywords: Chemo-resistance, Risk factors, Endometriosis associated ovarian cancer

\section{Background}

At present, many scholars regard endometriosis-associated ovarian cancer(EAOC) as a special pathological type of epithelial ovarian cancer(EOC), including ovarian clear cell carcinoma (OCCC) and endometrioid carcinoma. Studies have reported that the clinical features and prognosis of patients with EAOC were different from those with other EOCs. Compared with ovarian serous carcinoma, the onset age of OCCC was younger (55 vs 64 years; median age) [1]. A study comparing early ovarian cancer and advanced ovarian cancer (I/II vs. III/IV) reported that $57-81 \%$ of OCCC were diagnosed in early stage (I/II) [2]. Since most patients

\footnotetext{
* Correspondence: wangshu219@hotmail.com; XiangY@pumch.cn; langjh@hotmail.com

${ }^{\dagger}$ Tong Ren and Ting-Ting Sun contributed equally to this work.

1 Department of Obstetrics and Gynecology, Peking Union Medical College Hospital, Chinese Academy of Medical Science and Peking Union Medical College, 1 ShuaiFuYuan, DongCheng District, Beijing 100730, China

Full list of author information is available at the end of the article
}

of OCCC were with unilateral pelvic mass of early stage, their prognosis was better than other types of EOC. The 5 -year survival rate of OCCC patients with early stage was higher than $80 \%$ [3]. However, the prognosis of those with advanced stage was poorer than that of other EOCs with the 5 -year survival rate about $20 \%$, which might be related to the resistance to platinum-based chemotherapy [4]. The clinical risk factors of chemo-resistance in patients with EAOC have not been reported. By retrospectively analyzing the data of EOC patients who received initial treatment in our hospital over a 12-year period, this study intended to analyze the clinical features and chemo-resistance related factors of patients with resistant and non-resistant EAOC (OCCC and endometrioid carcinoma), expecting to provide references for the guidance of clinical treatments and the prediction of survival outcomes.

(C) The Author(s). 2018 Open Access This article is distributed under the terms of the Creative Commons Attribution 4.0 International License (http://creativecommons.org/licenses/by/4.0/), which permits unrestricted use, distribution, and reproduction in any medium, provided you give appropriate credit to the original author(s) and the source, provide a link to the Creative Commons license, and indicate if changes were made. The Creative Commons Public Domain Dedication waiver (http://creativecommons.org/publicdomain/zero/1.0/) applies to the data made available in this article, unless otherwise stated. 
Table 1 Clinical and morphological characteristics of patients with or without chemo-resistance

\begin{tabular}{|c|c|c|c|c|c|}
\hline Variable & Category & Number(\%) & Chemo-sensitive(\%) & Chemoresistance(\%) & $P$ \\
\hline & & 304 & $252(82.9 \%)$ & $52(17.1 \%)$ & \\
\hline \multirow[t]{2}{*}{ Age } & $<48$ & $129(42.43)$ & 114(45.24) & 15(28.85) & $0.0294^{*}$ \\
\hline & $\geq 48$ & $175(57.57)$ & 138(54.76) & $37(71.15)$ & \\
\hline \multirow[t]{2}{*}{ Menopausal status } & Pre & $161(52.96)$ & 139(55.16) & $22(42.31)$ & 0.0909 \\
\hline & Post & 143(47.04) & 113(44.84) & $30(57.69)$ & \\
\hline \multirow[t]{2}{*}{ Gravidity } & $<1$ & $35(11.51)$ & $31(12.3)$ & $4(7.69)$ & 0.3431 \\
\hline & $>=1$ & 269(88.49) & $221(87.7)$ & 48(92.31) & \\
\hline \multirow[t]{2}{*}{ Parity } & $<1$ & $51(16.78)$ & $46(18.25)$ & $5(9.62)$ & 0.1290 \\
\hline & $>=1$ & 253(83.22) & 206(81.75) & 47(90.38) & \\
\hline \multirow[t]{2}{*}{ Abdominal pain } & No & $210(69.08)$ & 174(69.05) & $36(69.23)$ & 0.9016 \\
\hline & Yes & 93(30.59) & 77(30.56) & 16(30.77) & \\
\hline \multirow[t]{2}{*}{ Bloating } & No & $243(79.93)$ & 208(82.54) & $35(67.31)$ & $0.0125^{*}$ \\
\hline & Yes & 61(20.07) & $44(17.46)$ & 17(32.69) & \\
\hline \multirow[t]{2}{*}{ Palpable mass } & No & $223(73.36)$ & 182(72.22) & $41(78.85)$ & 0.3253 \\
\hline & Yes & $81(26.64)$ & $70(27.78)$ & $11(21.15)$ & \\
\hline \multirow[t]{2}{*}{ Incidental finding } & No & $256(84.21)$ & 208(82.54) & 48(92.31) & 0.0786 \\
\hline & Yes & 48(15.79) & 44(17.46) & $4(7.69)$ & \\
\hline \multirow[t]{2}{*}{ Irregular menstruation } & No & $275(90.46)$ & 226(89.68) & 49(94.23) & 0.3094 \\
\hline & Yes & $29(9.54)$ & 26(10.32) & $3(5.77)$ & \\
\hline \multirow[t]{2}{*}{ Postmenopausal bleeding } & No & 285(93.75) & 235(93.25) & $50(96.15)$ & 0.4316 \\
\hline & Yes & 19(6.25) & $17(6.75)$ & $2(3.85)$ & \\
\hline \multirow[t]{2}{*}{ Emaciation } & No & 294(96.71) & 248(98.41) & $46(88.46)$ & $0.0002^{*}$ \\
\hline & Yes & 10(3.29) & $4(1.59)$ & $6(11.54)$ & \\
\hline \multirow[t]{2}{*}{ Abnormal vaginal discharge } & No & 302(99.34) & 250(99.21) & $52(100)$ & 0.5192 \\
\hline & Yes & $2(0.66)$ & $2(0.79)$ & $0(0)$ & \\
\hline \multirow[t]{2}{*}{ Ca125 in normal range $(<35 \mathrm{U} / \mathrm{L})$} & No & 249(81.91) & 199(78.97) & $50(96.15)$ & $0.0034^{*}$ \\
\hline & Yes & $55(18.09)$ & $53(21.03)$ & $2(3.85)$ & \\
\hline \multirow[t]{2}{*}{ CA125group } & $<90$ & 112(36.84) & 104(41.27) & $8(15.38)$ & $0.0004^{*}$ \\
\hline & $\geq 90$ & 192(63.16) & 148(58.73) & $44(84.62)$ & \\
\hline \multirow[t]{2}{*}{ Early or late Stage } & $\mathrm{FIGO} I+\|$ & $185(60.86)$ & 175(69.44) & 10(19.23) & $<.0001^{*}$ \\
\hline & $\mathrm{FIGO} I I I+\mathrm{IV}$ & 119(39.14) & 77(30.56) & $42(80.77)$ & \\
\hline \multirow[t]{4}{*}{ FIGO stage ${ }^{a}$} & । & $141(46.38)$ & 136(53.97) & $5(9.62)$ & $<.0001^{*}$ \\
\hline & $\|$ & $44(14.47)$ & $39(15.48)$ & $5(9.62)$ & \\
\hline & III & 104(34.21) & $69(27.38)$ & $35(67.31)$ & \\
\hline & IV & 15(4.93) & $8(3.17)$ & $7(13.46)$ & \\
\hline \multirow[t]{2}{*}{ Tumor size group } & $<7$ & $80(26.32)$ & 66(26.19) & 14(26.92) & 0.9130 \\
\hline & $\geq 7$ & 224(73.68) & 186(73.81) & $38(73.08)$ & \\
\hline \multirow[t]{3}{*}{ Pathology Grade } & G1 & 45(24.19) & $44(28.03)$ & $1(3.45)$ & $0.0128^{*}$ \\
\hline & G2 & $59(31.72)$ & 49(31.21) & 10(34.48) & \\
\hline & G3 & $82(44.09)$ & $64(40.76)$ & 18(62.07) & \\
\hline \multirow[t]{2}{*}{ Pathology type } & Endometrioid & 186(61.18) & 157(62.30) & $29(55.77)$ & 0.435 \\
\hline & Clear cell & 118(38.82) & 95(37.70) & $23(44.23)$ & \\
\hline \multirow[t]{2}{*}{ Endometriosis } & No & 235(77.30) & 188(74.6) & 47(90.38) & $0.0134^{*}$ \\
\hline & Yes & $69(22.70)$ & $64(25.4)$ & $5(9.62)$ & \\
\hline
\end{tabular}


Table 1 Clinical and morphological characteristics of patients with or without chemo-resistance (Continued)

\begin{tabular}{|c|c|c|c|c|c|}
\hline Variable & Category & Number(\%) & Chemo-sensitive(\%) & Chemoresistance(\%) & $P$ \\
\hline \multirow[t]{2}{*}{ Side of tumor } & Unilateral & $212(69.74)$ & 183(72.62) & $29(55.77)$ & $0.0160^{*}$ \\
\hline & Bilateral & $92(30.26)$ & $69(27.38)$ & $23(44.23)$ & \\
\hline \multirow[t]{3}{*}{ LN metastasis } & No & 213(70.07) & 195(77.38) & 18(34.62) & $<.0001^{*}$ \\
\hline & Yes & $40(13.16)$ & $24(9.52)$ & $16(30.77)$ & \\
\hline & unclear & $51(16.78)$ & $33(13.1)$ & 18(34.62) & \\
\hline \multirow[t]{2}{*}{ LN dissection } & No & $51(16.78)$ & $33(13.1)$ & 18(34.62) & $0.0002^{*}$ \\
\hline & Yes & $253(83.22)$ & 219(86.9) & $34(65.38)$ & \\
\hline \multirow[t]{2}{*}{ Residual disease } & No & $231(75.99)$ & 207(82.14) & $24(46.15)$ & $<.0001^{*}$ \\
\hline & Yes & $73(24.01)$ & $45(17.86)$ & $28(53.85)$ & \\
\hline \multirow[t]{2}{*}{$\mathrm{TH}$} & No & 297(97.7) & $246(97.62)$ & $51(98.08)$ & 0.8411 \\
\hline & Yes & $7(2.3)$ & $6(2.38)$ & $1(1.92)$ & \\
\hline \multirow[t]{2}{*}{ Tubal ligation } & No & 290(95.39) & 243(96.43) & $47(90.38)$ & 0.0583 \\
\hline & Yes & $14(4.61)$ & $9(3.57)$ & $5(9.62)$ & \\
\hline \multirow[t]{2}{*}{ Sterilization surgery } & No & 283(93.09) & 237(94.05) & $46(88.46)$ & 0.1481 \\
\hline & Yes & $21(6.91)$ & 15(5.95) & 6(11.54) & \\
\hline \multirow[t]{2}{*}{ Endometrial disorder } & No & $252(82.89)$ & 208(82.54) & $44(84.62)$ & 0.7174 \\
\hline & Yes & $52(17.11)$ & $44(17.46)$ & 8(15.38) & \\
\hline \multirow[t]{4}{*}{ Variable endometrial disorder } & No & $252(82.89)$ & 207(82.14) & $45(86.54)$ & 0.7998 \\
\hline & EP & $27(8.88)$ & 23(9.13) & $4(7.69)$ & \\
\hline & EIN & $22(7.24)$ & 19(7.54) & $3(5.77)$ & \\
\hline & EC & $3(0.99)$ & $3(1.19)$ & $0(0)$ & \\
\hline \multirow[t]{2}{*}{ Breast cancer } & No & 296(97.37) & 248(98.41) & $48(92.31)$ & $0.0123^{*}$ \\
\hline & Yes & $8(2.63)$ & $4(1.59)$ & $4(7.69)$ & \\
\hline \multirow[t]{2}{*}{ HT } & No & $250(82.24)$ & 208(82.54) & $42(80.77)$ & 0.7610 \\
\hline & Yes & $54(17.76)$ & $44(17.46)$ & 10(19.23) & \\
\hline \multirow[t]{2}{*}{ DM } & No & 286(94.08) & 236(93.65) & $50(96.15)$ & 0.4862 \\
\hline & Yes & 18(5.92) & 16(6.35) & $2(3.85)$ & \\
\hline
\end{tabular}

${ }^{\mathrm{a}}$ According to the classification system of FIGO staging (2013 version)

Abbreviation: Ca125 cancer antigen 125, EM endometriosis, LN lymph node, TH total hysterectomy, EP endometrial polyps, EIN endometrial intraepithelial neoplasm, EC endometrial cancer, $H T$ hypertension, DM diabetic mellitus

${ }^{*} P<0.05$

\section{Results}

A total of 304 patients diagnosed with EAOC and treated in PUMCH were identified, 52(17.1\%) of which were seen with platinum-based drug resistance and the rest $252(82.9 \%)$ were in the non-resistant group. Table 1 showed the demographic and clinical characteristics of all the patients. In this study, based on the ROC curve of chemo-resistance, the above continuous variables were grouped by age, tumor size and Ca125 level[age: $<48$ or $\geq$ 48 years; tumor size: $<7 \mathrm{~cm}$ or $\geq 7 \mathrm{~cm}$; Ca125: $<90 \mathrm{U} / \mathrm{L}$ or $\geq 90 \mathrm{U} / \mathrm{L}$ ], as seen in Fig. 1. Univariate analysis showed that compared with the non-resistant group, there were more patients with age $\geq 48$ years in the chemo-resistant group ( $71.15 \%$ vs $54.76 \%, P=0.0294$ ), more with symptoms of abdominal distension (32.69\% vs $17.46 \%, P=0.0125)$ and emaciation ( $11.54 \%$ vs $1.59 \%, P=0.0002)$, fewer with normal level of Ca125 (3.85\% vs $21.03 \%, P=0.0034)$ but more
$\mathrm{Ca} 125<90 \mathrm{U} / \mathrm{L}(84.62 \%$ vs $58.73 \%, P=0.0004)$, more advanced FIGO stage(III + IV) $(80.77 \%$ vs $30.56 \%, P<0.001)$, more high-grade tumor(62.07\% vs $40.76 \% ; P=0.0128)$, fewer coexisting endometriosis $(9.62 \%$ vs $25.4 \%, P=$ $0.0134)$, more bilateral tumors $(44.23 \%$ vs $27.38 \%, P=$ $0.0160)$, more positive LNs $(30.77 \%$ vs $9.52 \%, P<0.001)$, fewer lymphadenectomy ( $34.62 \%$ vs $13.1 \%, P=0.0002)$, more residual tumor $>1 \mathrm{~cm}$ and more history of breast cancer $(7.69 \%$ vs $1.59 \%, P=0.0123)$. Meanwhile, there was no statistically significant difference seen in menopause status, number of pregnancies and labors, tumor size, histologic type, coexisting endometrial lesions, history of hysterectomy or tubal sterilization and history of diabetes mellitus or hypertension, as showed in Table $1(P>0.05)$.

In multivariate analysis however, only FIGO stage $(P=$ $0.004)$, positive LNs $(P=0.040)$, lymph nodes resection $(P=0.016)$ and history of breast cancer $(P=0.044)$ were 


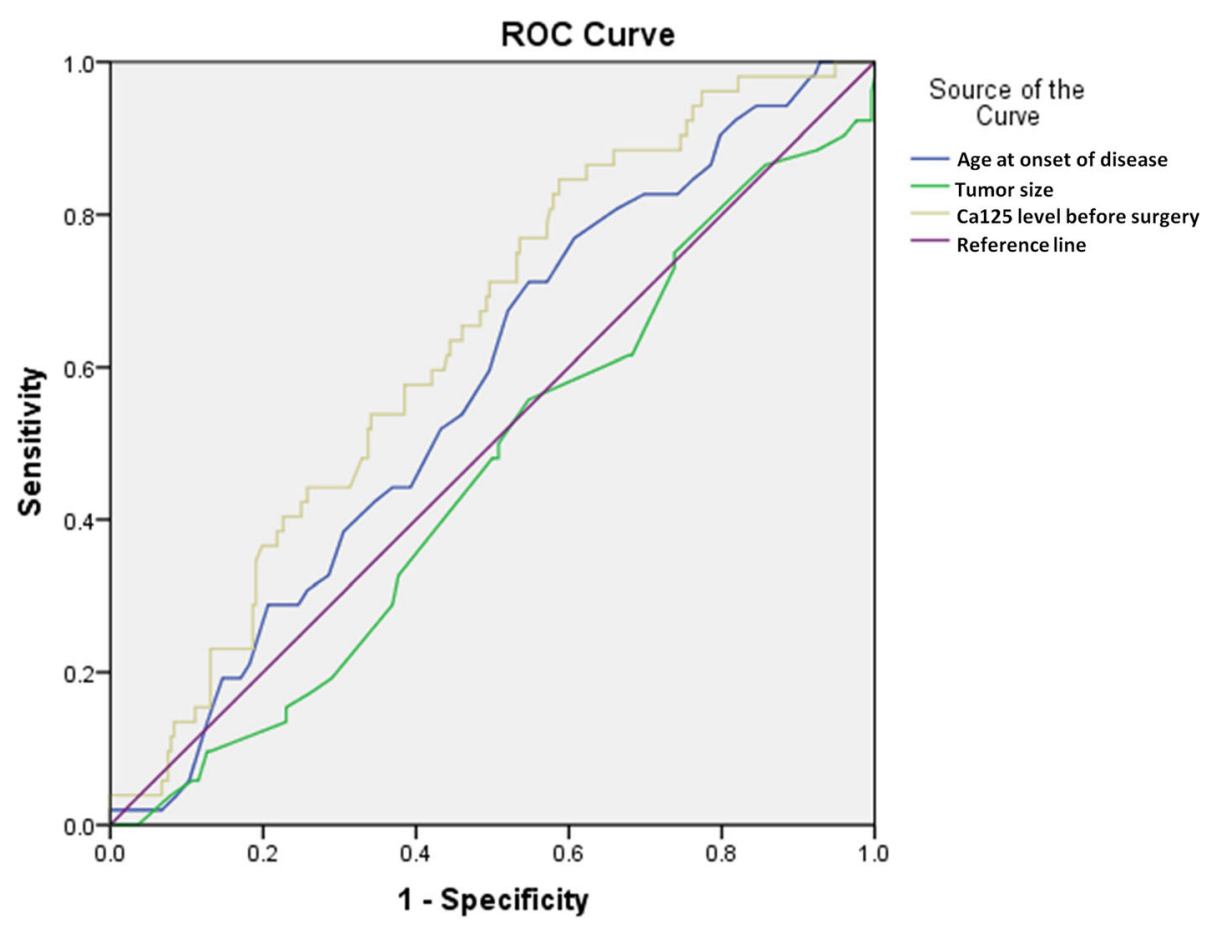

Fig. 1 ROC curve for age of disease onset, tumor size, pre-surgery Ca125 in the occurrence of chemo-resistance

independent risk factors of platinum-based drug resistance, while onset age, initial symptoms, Ca125 level, coexisting endometriosis and residual tumors were not, as seen in Table 2.

\section{Discussion}

This study regarded OCCC and ovarian endometrioid carcinoma as a whole of EAOC for the first time and

Table 2 Multivariate analysis of risk factors of chemo-resistance among endometriosis related ovarian cancer patients

\begin{tabular}{lllll}
\hline & B & S.E. & P & OR(95\%Cl) \\
\hline Age & .337 & .395 & .393 & $1.4(0.65 \sim 3.04)$ \\
Bloating & -.057 & .401 & .886 & $0.94(0.43 \sim 2.07)$ \\
Emaciation & 1.447 & .791 & .067 & $4.25(0.9 \sim 20.02)$ \\
Ca125 in normal range & .728 & .797 & .361 & $2.07(0.43 \sim 9.87)$ \\
EM & -.016 & .573 & .978 & $0.98(0.32 \sim 3.03)$ \\
FIGO stage ${ }^{a}$ & 1.422 & .497 & $.004^{*}$ & $4.15(1.57 \sim 10.97)$ \\
LN metastasis & .980 & .477 & $.040^{*}$ & $2.66(1.05 \sim 6.78)$ \\
LN dissection & 1.059 & .440 & $.016^{*}$ & $2.88(1.22 \sim 6.82)$ \\
Residual disease & .396 & .405 & $.328^{*}$ & $1.49(0.67 \sim 3.29)$ \\
Breast cancer & 1.851 & .918 & $.044^{*}$ & $6.37(1.05 \sim 38.49)$ \\
Constant & -5.388 & 1.018 & .000 & \\
\hline
\end{tabular}

*The difference reached statistical significance. $P$ values were cultivated by Cox regression analysis. The overall test of the above model showed the model was significance, $p<0.0001$

${ }^{a}$ According to the classification system of FIGO staging (2013 version) Abbreviation: Ca125 cancer antigen 125, EM endometriosis, LN lymph node investigated the clinicopathological risk factors of platinum-based chemoresistance. Univariate analysis showed that age, higher level of Ca125, advanced FIGO stage, high-grade tumor, absence of endometriosis, bilateral tumors, lack of lymphadenectomy, positive LNs, residual lesion $>1 \mathrm{~cm}$ and history of breast cancer were related to chemoresistance. However, multivariate analysis showed that FIGO stage, lack of lymphadenectomy, positive LNs and history of breast cancer were independent risk factors associated with drug resistance to platinum in patients with such type of EOC.

A large number of previous studies focused on the drug resistance in OCCC. Some retrospective studies have shown that OCCC was resistant to traditional platinum-based chemotherapy regimens with an objective effective rate of $11-27 \%$, while the response rate of serous adenocarcinoma (SAC) was $73-81 \%$, significantly higher than that of OCCC [5-7]. Utsunomiya et al. found that the effective rate of paclitaxel plus carboplatin (TC) regimen in patients with OCCC was not high either [8]. Rauh-Hain et al. reported that the response rate of 121 OCCC patients treated with first-line platinum-based chemotherapy regimens was 79 and $24 \%$ of the patients relapsed within 6 months after the last cycle of chemotherapy of initial treatments [9]. Moreover, their results showed that unsatisfactory cytoreductive surgery and wide dissemination of tumors were significantly associated with platinum resistance by multivariate logistic regression analysis. On the other hand, Liang et al. have 
reported that advanced stage, poor differentiation, LN positivity, CA125 level $>1000 \mathrm{U} / \mathrm{mL}$ and suboptimal cytoreductive surgery would lead to drug resistance or partial sensitivity to chemotherapy during the treatment of OCCC. These results were not in full accord with the findings of this study [10].

The mechanism of drug resistance to chemotherapy in OCCC was complex, which might be related to the low proliferation rate of the tumors, the increase of damage to DNA repair activity, the up-regulation of growth factor signaling pathway and the abnormal expression of microtubule-disaggregated protein, etc. Studies have shown that the high resistance of OCCC to chemotherapy might be related to its low cell proliferation rate [4]. Itamochi et al. reported that the doubling time for tumor cells of OCCC was significantly longer than that of SAC (61.4 vs $29.8 \mathrm{~h})$ [11]. Ki-67 protein was expressed at various stages of the cell cycle, representing the proliferative activity of the cells, and its expression in OCCC was significantly lower than that in SAC. In addition, the Ki-67 labelling index (LI) in patients that are resistant to platinum-based chemotherapy was significantly lower than it in those sensitive (15.3\% vs $30.2 \%)$ [4]. As known, platinum-based drugs inhibited the proliferation of tumor cells mainly by hindering the replication of DNA. Therefore, the low proliferation rate of OCCC cells enabled them to some extent to be tolerant to platinum-based drugs targeting on DNA, which suggested that the chemoresistance of OCCC might be associated with its low proliferation rate [12].

Previous studies have showed tumors lack of DNA mismatch repair (MMR) system were highly resistant to certain methylated drugs of chemotherapy in vitro [13]. The function of MMR is to correct mistakes in DNA replication and play an important role in the sensitivity of DNA damage factors. MMR deficiency might result from germline mutations of two major MMR genes, such as hMLH1 and hMSH2, as well as epigenetic silencing due to the methylation of the hMLH1 promoter, leading to inactivation of the gene system. Cai et al. reported that the high expression of mutations in hMLH1 and hMSH2 existed in OCCC and was associated with its development [14]. In addition, Niimi $\mathrm{K}$ et al. also reported that the expression of DNA damage repair related protein REV7 in OCCC was significantly higher than that in other types of EOCs (73.5\% vs $53.4 \%$ ), and the knockdown of REV gene could induce apoptosis and DNA damage in tumor cells, leading to a significant improvement of chemoresistance to cisplatin in OCCC [15]. On the other hand, Itamochi $\mathrm{H}$ et al. reported that the use of $\mathrm{CHK}$ inhibitors could improve the drug resistance of OCCC to cisplatin [16], while the main function of cell cycle checkpoint kinase (CHK) was to regulate the synthesis of DNA in tumor cells.
In addition, the up-regulation of growth factor signaling pathway is related to drug resistance in tumor. As cell surface receptor tyrosine kinase, epidermal growth-factor receptor (EGFR) can activate the mitogen-activated protein kinase pathway, thus inhibiting the apoptosis induced by chemotherapy drugs [17]. An immunohistochemical study showed that EGFR could be found in $61 \%$ of CCC, and the overexpression of EGFR might be related to chemotherapy resistance and poor prognosis of ovarian cancer [18]. Siddiqui GK et al. reported that in platinum-resistant group, the proportion of patients with high expression of VEGF in tumor tissues was significantly higher than it in the platinum-sensitive group ( $86 \%$ vs $2 \%$ ), suggesting that the resistance of EOC to platinum-based chemotherapy was related to VEGR expression [19]. Mabuchi $S$ et al. confirmed in vitro that the expression of VEGF in cisplatin-resistant OCCC cell lines was significantly higher than that in cisplatin-sensitive OCCC cell lines, suggesting that the generation of drug resistance might be related to the angiogenesis in the tumors [20]. According to previous literatures, the expression of HER2 in OCCC was much higher than it in other major histological types of EOCs, and tumors with overexpression of HER2 showed low sensitivity to traditional anti-tumor drugs, leading to the poor prognosis of these patients [21, 22].

Studies about the drug resistance in ovarian endometrioid carcinoma was limited. Pylväs-Eerola et al. have reported that the preoperative level of 8-hydroxy-2-deoxyguanosine in patients were significantly associated with chemoresistance of ovarian endometrioid carcinoma, which could be used as a factor for resistance prediction [23].

Our results showed that histologic type indicating OCCC or endometrioid carcinoma was not an independent risk factor of platinum-based drug resistance $(55.77 \%$ vs $44.23 \%$, $P=0.435$ ), which was not consistent with previous studies, suggesting that the platinum-based drug resistance in these two types of tumors might have similarities. More molecular biological researches were expected to explore the molecular mechanism of chemoresistance in EAOC.

\section{Conclusion}

This study regarded endometriosis-related OCCC and endometrioid carcinoma as a whole of EAOC for the first time and analyzed the clinicopathological risk factors of platinum-based chemoresistance. Multivariate analysis showed that FIGO stage, positive LNs, lack of lymphadenectomy and history of breast cancer were independent risk factors of drug resistance in patients with EAOC. This finding is of certain value for predicting platinum-based drug resistance in the treatment of EAOC, which may give some instructions for designing individualized chemotherapy regimens. In the future, it is expected to 
carry out more accurate molecular typing for such patients through molecular biological study, which can be used to guide precise medication of chemotherapy drugs for patients with ovarian cancers.

\section{Methods}

This is a retrospective study conducted at Department of Obsterics and Gynecology, Peking Union Medical College Hospital(PUMCH). We identified all the 304 patients who received surgical treatments and postoperative chemotherapy from January 2000 to December 2012, including 118 cases of OCCCs and 186 cases of endometrioid carcinomas confirmed by postoperative histopathology. All patients with EAOC of early stage (stage I and II) have received completed staging surgery; and those of advanced stage (stage III and IV) have undergone optimal CRS, except for those with unresectable tumors who received suboptimal CRS. They all received adjuvant chemotherapy of platinum-based regimens after primary surgery.

The clinicopathologic data of patients with EAOC were collected, including age, initial symptoms, menopause status, number of pregnancies and labors, previous medical complications, preoperative CA125 level, FIGO stage, tumor size, laterality, histologic type, grade, coexisting endometriosis, lymph nodes(LNs) metastasis, lymphadenectomy (the resection of pelvic LNs with or without para-aortic LNs), residual tumor, history of hysterectomy and tubal ligation, coexisting endometrial lesions (including endometrial polyps, atypical hyperplasia and endometrial cancer), history of breast cancer, history of hypertension and diabetes. Platinum-based drug resistance in ovarian cancer was defined as a definite progression or recurrence of disease within 6 months after completing the last cycle of chemotherapy for initial treatments. In this study, we defined ovarian cancer concurrent with endometriosis as the presence of ovarian cancer and endometriosis identified histologically in the same ovary, the presence of endometriosis in one ovary and ovarian cancer in the contralateral ovary, or the presence of ovarian cancer and extraovarian pelvic endometriosis (eg, peritoneal endometriosis).

SPSS 22.0 was used for statistical analysis. Continuous variables were analyzed using an independent-sample $t$ test. Categorical variables were analyzed using $X^{2}$ test or Fisher's exact test. Odds ratio (OR) and 95\% confidence interval (CI) were calculated. The effects of clinicopathological characteristics on chemoresistance in EAOC were assessed using logistic regression models through univariate and multivariate analysis. Receiver Operating Characteristic (ROC) curve was constructed to define the optimal cutoff value for stratifying and grouping. All statistical tests were two-sided and differences were considered statistically significant at $P<0.05$.

\section{Abbreviations}

Ca125: Cancer antigen 125; DFS: Disease-free survival; EAOC: Endometriosisassociated ovarian cancer; EAOCCC: Endometriosis-associated ovarian clear cell carcinoma; EAOEC: Endometriosis-associated ovarian endometrioid carcinoma; OS: Overall survival

\section{Acknowledgements}

We appreciate the gynecologists at Peking Union Medical College Hospital for their diligent clinical work and precise data recording about the cases we reported in this article.

\section{Funding}

This study was funded by National Key R\&D Program of China (No.SQ2017YFSF080001) and National Natural Science Foundation of China (No. 81501236).

\section{Availability of data and materials}

The dataset supporting the conclusions of this article is included within the article and its additional files.

\section{Authors' contributions}

TR and TS make substantial contributions to conception and design, analysis and interpretation of data, and drafting the article. JS has reviewed the pathological slides. WS, YX and JL have designed the study and participate in revising it critically for important intellectual content. KS have contributed to some valuable advice during preparing this paper. All authors read and approved the final manuscript.

Ethics approval and consent to participate

Obstetrics and Gynecology Peking Union Medical College Hospital Human Research Ethics Committee Approval was obtained for the use of all samples.

\section{Competing interests}

The authors declare that they have no competing interests.

\section{Publisher's Note}

Springer Nature remains neutral with regard to jurisdictional claims in published maps and institutional affiliations.

\section{Author details}

${ }^{1}$ Department of Obstetrics and Gynecology, Peking Union Medical College Hospital, Chinese Academy of Medical Science and Peking Union Medical College, 1 ShuaiFuYuan, DongCheng District, Beijing 100730, China.

${ }^{2}$ Department of Pathology, Peking Union Medical College Hospital, Chinese Academy of Medical Science and Peking Union Medical College, Beijing, People's Republic of China.

Received: 12 February 2018 Accepted: 20 May 2018

Published online: 29 May 2018

\section{References}

1. Chan JK, Teoh D, Hu JM, Shin JY, Osann K, Kapp DS. Do clear cell ovarian carcinomas have poorer prognosis compared to other epithelial cell types? A study of 1411 clear cell ovarian cancers. Gynecol Oncol. 2008;109:370-6.

2. Behbakht K, Randall TC, Benjamin I, Morgan AM, King S, Rubin CS. Clinical characteristics of clear cell carcinoma of the ovary. Gynecol Oncol. 1998;70: 255-8.

3. Sugiyama T, Kamura T, Kigawa J, Terakawa N, Kikuchi Y, Kita T, et al. Clinical characteristics of clear cell carcinoma of the ovary. A distinct histologic type with poor prognosis and resistance to platinum-based chemotherapy. Cancer. 2000;88:2584-9.

4. Itamochi H, Kigawa J, Sugiyama T, et al. Low proliferation activity may be associated with chemoresistance in clear cell carcinoma of the ovary[J]. Obstet Gynecol. 2002;100(2):281-7.

5. Mackay HJ, Brady MF, Oza AM, Reuss A, Pujade-Lauraine E, Swart AM, et al. Gynecologic Cancer InterGroup. Prognostic relevance of uncommon ovarian histology in women with stage III/IV epithelial ovarian cancer. Int J Gynecol Cancer. 2010;20:945-52.

6. FC1 K, RC2 W, LY3 Y, et al. Clear cell carcinomas of the ovary have poorer outcomes compared with serous carcinomas: Results from a single-center Taiwanese study. J Formos Med Assoc. 2018;117:117-25. 
7. Miyamoto M, Takano M, Goto T, et al. Clear cell histology as a poor prognostic factor for advanced epithelial ovarian cancer: a single institutional case series through central pathologic review [J]. J Gynecol Oncol. 2013:24(1):37-43.

8. Enomoto TKC, Yamasaki M, Kuragaki M, Sagita Y, Otsuki H, Ikegami N, et al. Is clear cell carcinoma and mucinous carcinoma of the ovary sensitive to combination chemotherapy with paclitaxel and carboplatin? Proc Am Soc Clin Oncol. 2003;22:1797.

9. Rauh-Hain AJ, Winograd D, Growdon WB, Schorge JO, Goodman AK, Boruta $\mathrm{DM}$, et al. Prognostic determinants in patients with uterine and ovarian clear cell carcinoma. Gynecol Oncol. 2012;125:376-80.

10. Liang XD, Zeng HX, Zhu HL, Feng YY, Yin LY, Cui H, Wei LH. Prediction of chemoresistance in epithelial ovarian cancer by clinical factors. Zhonghua $Y_{i}$ Xue Za Zhi. 2011;91(29):2030-3.

11. Itamochi H, Kigawa J, Akeshima R, et al. Mechanisms of cisplatin resistance in clear cell carcinoma of the ovary. Oncology. 2002;62:349Y353.

12. Itamochi H, Kigawa J, Terakawa N. Mechanisms of chemoresistance and poor prognosis in ovarian clear cell carcinoma. Cancer Sci. 2008;99:653Y658.

13. Claij N, te Riele H. Microsatellite instability in human cancer: a prognostic marker for chemotherapy? Exp Cell Res. 1999;246:1-10.

14. Cai $\mathrm{KQ}$, Albarracin $\mathrm{C}$, Rosen $\mathrm{D}$, et al. Microsatellite instability and alteration of the expression of hMLH1 and hMSH2 in ovarian clear cell carcinoma. Hum Pathol. 2004;35:552-9.

15. Niimi K, Murakumo Y, Watanabe N, et al. Suppression of REV7 enhances cisplatin sensitivity in ovarian clear cell carcinoma cells. Cancer Sci. 2014 105(5):545-52.

16. Itamochi $\mathrm{H}$, Nishimura $\mathrm{M}$, Oumi N, et al. Checkpoint kinase inhibitor AZD7762 overcomes cisplatin resistance in clear cell carcinoma of the ovary. Int J Gynecol Cancer. 2014;24(1):61-9.

17. Johnstone RW, Ruefli AA, Lowe SW. Apoptosis. a link between cancer genetics and chemotherapy. Cell. 2002;108:153-64.

18. Fujimura M, Hidaka T, Saito S. Selective inhibition of the epidermal growth factor receptor by ZD1839 decreases the growth and invasion of ovarian clear cell adenocarcinoma cells. Clin Cancer Res. 2002;8:2448-54.

19. Siddiqui GK, Maclean $A B$, Elmasry K, et al. Immunohistochemical expression of VEGF predicts response to platinum based chemotherapy in patients with epithelial ovarian cancer. Angiogenesis. 2011:14(2):155-61.

20. Mabuchi S, Kawase C, Altomare DA, et al. Vascular endothelial growth factor is a promising therapeutic target for the treatment of clear cell carcinoma of the ovary. Mol Cancer Ther. 2010;9(8):2411-22.

21. Rowinsky EK, Donehower RC, Jones RJ, Tucker RW. Microtubule changes and cytotoxicity in leukemic cell lines treated with taxol. Cancer Res. 1988: 48:4093-100.

22. Rolitsky CD, Theil KS, McGaughy VR, Copeland LJ, Niemann TH. HER-2/neu amplification and overexpression in endometrial carcinoma. Int J Gynecol Pathol. 1999:18:138-43.

23. M P-E, P K, U P. Preoperative serum 8-hydroxydeoxyguanosine is associated with chemoresistance and is a powerful prognostic factor in endometrioidtype epithelial ovarian cancer. BMC Cancer. 2015;15:493.

\section{Ready to submit your research? Choose BMC and benefit from:}

- fast, convenient online submission

- thorough peer review by experienced researchers in your field

- rapid publication on acceptance

- support for research data, including large and complex data types

- gold Open Access which fosters wider collaboration and increased citations

- maximum visibility for your research: over $100 \mathrm{M}$ website views per year

At BMC, research is always in progress.

Learn more biomedcentral.com/submissions 